\title{
Effect of $\mathrm{Ta}_{2} \mathrm{O}_{5}, \mathrm{Nb}_{2} \mathrm{O}_{5}$, and $\mathrm{HfO}_{2}$ Alloying on the Transformability of $\mathrm{Y}_{2} \mathrm{O}_{3}$-Stabilized Tetragonal $\mathrm{ZrO}_{2}$
}

\author{
Dae-Joon Kim*** \\ Department of Materials Science and Engineering, The University of Michigan, \\ Ann Arbor, Michigan 48109
}

\begin{abstract}
The addition of $\mathrm{Ta}_{2} \mathrm{O}_{5}, \mathrm{Nb}_{2} \mathrm{O}_{5}$, and $\mathrm{HfO}_{2}$ enhanced the transformability of $\mathrm{Y}_{2} \mathrm{O}_{3}$-stabilized tetragonal $\mathrm{ZrO}_{2}$ polycrystal (Y-TZP), which was indicated by an increase in phase transformation temperatures and fracture toughness of Y-TZP. Comparison of the alloying effects of these oxides on the transformability and crystal structure of Y-TZP suggested that an alloying oxide which increases the $c / a$ axial ratio (tetragonality) of TZP also increases the transformability. Empirical equations to predict the tetragonality are proposed. Calculated tetragonalities showed good agreement with measured values in the systems $\mathrm{ZrO}_{2}-\mathrm{Y}_{2} \mathrm{O}_{3}-\mathrm{Ta}_{2} \mathrm{O}_{5}$, $-\mathrm{Nb}_{2} \mathrm{O}_{5}$, and $-\mathrm{HfO}_{2}$. [Key words: yttria, zirconia, alloys, transformations, fracture toughness.]
\end{abstract}

\section{Introduction}

$\mathbf{I}$ T Is well-known that for $\mathrm{ZrO}_{2}$ to be utilized for technical applications the high-temperature polymorphs, namely, cubic $(c)$ and tetragonal $(t)$ phases, should be stabilized at ambient temeprature by the formation of solid solutions which prevent deleterious tetragonal-to-monoclinic $(m)$ phase transformation. The alloying oxides which lead to the stabilization are alkaline-earth, rare-earth, and actinide oxides and some transition-element oxides such as $\operatorname{In}_{2} \mathrm{O}_{3}{ }^{1}$ Although there is no theoretical basis to select the stabilizer, it has been suggested that the factors which may influence the stabilization are size, valency, and concentration of solute cations and crystal structure of the solute oxide, ${ }^{2}$ where the valency and concentration determine the number of oxygen vacancies created by the formation of substitutional solid solutions.

$\mathrm{Y}_{2} \mathrm{O}_{3}$ is a very effective stabilizer for $t-\mathrm{ZrO}_{2}$, which possesses high values of strength and fracture toughness with an optimum amount of $\mathrm{Y}_{2} \mathrm{O}_{3}$ concentration. ${ }^{3,4}$ The $t-\mathrm{ZrO}_{2}$ phase retention at room temperature in this system depends on the composition, grain size, and density of the $\mathrm{Y}_{2} \mathrm{O}_{3}$-stabilized $t-\mathrm{ZrO}_{2}$ polycrystal (Y-TZP). ${ }^{5}$ For a given grain size and density, the addition of $\mathrm{Y}_{2} \mathrm{O}_{3}$ to $\mathrm{ZrO}_{2}$ lowers the transformation temperatures of $t \rightarrow m\left(M_{s}\right)$ and $m \rightarrow t\left(A_{s}\right){ }^{6}$ so that the chemical driving force for the transformation is reduced with increasing $\mathrm{Y}_{2} \mathrm{O}_{3}$ concentration. ${ }^{7}$ Thus the transformability or instability of Y-TZP decreases as the $\mathrm{Y}_{2} \mathrm{O}_{3}$ content increases. This lowered transformability is manifested by a small amount of $m-\mathrm{ZrO}_{2}$ fraction observed on the fracture surface of Y-TZP and is accompanied by a decrease in the fracture toughness. ${ }^{8}$

Schubert ${ }^{9}$ has related the compositional dependence of the stability of TZP in this system to its dependence on the thermal expansion anisotropy $(\Delta \alpha)$, which decreases with increasing $\mathrm{Y}_{2} \mathrm{O}_{3}$ concentration. $\Delta \alpha$ is known to govern the residual stress in $t-\mathrm{ZrO}_{2}$ so that the increased residual stress enhances the transformability. ${ }^{7,9}$ Since the $\Delta \alpha$ of Y-TZP decreases with

Manuscript No. 198740. Received December 15, 1988; approved May 24, 1989. Presented in part at the 89 th Annual Meeting of the American Ceramic Society, Pittsburgh, PA, April 28, 1987 (Basic Science Division, Paper No. 126-B-87)

* Member, the American Ceramic Society.

* Now at Oak Ridge National Laboratory, Oak Ridge, TN. increasing $\mathrm{Y}_{2} \mathrm{O}_{3}$ content, it was expected that the composition at which the $\Delta \alpha$ becomes zero would coincide with that at which $c-\mathrm{ZrO}_{2}$ becomes stable. ${ }^{9}$ However, the composition determined from the linear extrapolation of the $\Delta \alpha$ to zero was very different from the composition for $c-\mathrm{ZrO}_{2}$ obtained from the measurement of lattice parameters. ${ }^{10}$ Consequently, the effect of alloying on the transformability cannot be predicted by the effect on the $\Delta \alpha$ alone. On the other hand, the alloying of $\mathrm{HfO}_{2}$ into $\mathrm{ZrO}_{2}$ raises the $A_{s}$ and $M_{s}$ temperatures, ${ }^{11}$ which is attributed to an increase in the driving force for the $t \rightarrow m$ transformation. ${ }^{12,13}$ The increased $M_{s}$ due to $\mathrm{HfO}_{2}$ alloying has been interpreted by Burke and Garvie ${ }^{14}$ using the concept of the soft phonon mode. In their argument $M_{s}$ increases with decreasing effective cation mass of the resulting solid solution, which is decreased by the addition of $\mathrm{HfO}_{2}$. This simple interpretation is not applicable to changes in $M_{s}$ in the other $\mathrm{ZrO}_{2}$ solid solutions since these solid solutions cannot conform to the assumption that $\mathrm{ZrO}_{2}$ and a solute are identical with the exception of cation masses.

In the present paper, a systematic investigation of the effect of ternary element alloying on the transformability of Y-TZP was conducted in an effort to elucidate the origin of the compositional dependence of the transformability of $t-\mathrm{ZrO}_{2}$. Primarily, the effect of $\mathrm{Ta}_{2} \mathrm{O}_{5}$ alloying on the transformation temperatures, fracture toughness, and lattice parameters of YTZP was investigated. In addition, $\mathrm{Nb}_{2} \mathrm{O}_{5}$ and $\mathrm{HfO}_{2}$ were employed separately as ternary allowing oxides in YTZP to add to a generalization of the role of alloying oxides on the transformability. An effort was made to predict the alloying effect on the transformability which leads to a selection criterion for the stabilizer of $t-\mathrm{ZrO}_{2}$.

\section{Experimental Procedure}

Starting powders were prepared by coprecipitation from aqueous solutions of $\mathrm{Zr}\left(\mathrm{SO}_{4}\right)_{2} \cdot 4 \mathrm{H}_{2} \mathrm{O}, \mathrm{Y}\left(\mathrm{NO}_{3}\right)_{3} \cdot 6 \mathrm{H}_{2} \mathrm{O}$, and $\mathrm{TaCl}_{5}, \mathrm{NbCl}_{5}$, or $\mathrm{HfOCl}_{2} \cdot 8 \mathrm{H}_{2} \mathrm{O}$ with ammonia. For some compositions in the system $\mathrm{ZrO}_{2}-\mathrm{Y}_{2} \mathrm{O}_{3}-\mathrm{Nb}_{2} \mathrm{O}_{5}, \mathrm{ZrOCl}_{2}$ $8 \mathrm{H}_{2} \mathrm{O}$ was used for $\mathrm{ZrO}_{2}$ because of the decomposition of $\mathrm{Zr}\left(\mathrm{SO}_{4}\right)_{2} \cdot 4 \mathrm{H}_{2} \mathrm{O}$ with high concentration of $\mathrm{NbCl}_{5}$ solution in an aqueous mixture. The precipitates were dried for $20 \mathrm{~h}$ at $120^{\circ} \mathrm{C}$ after washing with distilled water and decomposed to the oxides by calcination for $3 \mathrm{~h}$ at $920^{\circ} \mathrm{C}$. The oxide agglomerates which contained $\mathrm{Ta}_{2} \mathrm{O}_{5}$ or $\mathrm{HfO}_{2}$ were dry-milled in a planetary mill using an alumina jar and balls. The powders in the system $\mathrm{ZrO}_{2}-\mathrm{Y}_{2} \mathrm{O}_{3}-\mathrm{Nb}_{2} \mathrm{O}_{5}$ were obtained by attrition milling in isopropyl alcohol using $\mathrm{ZrO}_{2}$ balls. Bend test specimens were prepared by pressing the powders isostatically at $170 \mathrm{MPa}$, and sintering for $1 \mathrm{~h}$ at $1500^{\circ} \mathrm{C}$. The density of sintered specimens was determined by the Archimedes method.

The fracture toughness was determined by two methods. One method involved the fracture of polished four-point bend specimens of dimensions $2.5 \mathrm{~mm} \times 3.0 \mathrm{~mm} \times 30 \mathrm{~mm}$ containing three 147-N Vickers indentations on the tensile surface within the inner span after Cook and Lawn. ${ }^{15}$ The dimensions of the inner and outer spans were 10 and $20 \mathrm{~mm}$, respectively. The samples were tested at a crosshead speed of $0.5 \mathrm{~mm} / \mathrm{min}$. 
The fracture toughness of each composition was obtained from an average value of three measurements. The other method employed the indentation technique applying the equation proposed by Anstis et al., ${ }^{16}$ where the value of $205 \mathrm{GPa}$ was used for the modulus of TZP. For the indentation method the indent load was varied from 196 to $490 \mathrm{~N}$ and the value of the fracture toughness was determined again by the average of three measurements. Four-point bend strength was obtained from the fracture of the bend specimens also at a crosshead speed of $0.5 \mathrm{~mm} / \mathrm{min}$.

The monoclinic fraction on the specimens was determined from X-ray diffractometer (XRD) peak intensities after Garvie and Nicholson. ${ }^{17}$ A dilatometer was used to measure the $A_{s}$ and $M_{s}$ transformation temperatures, which correspond to the starting points of the discontinuous volume shrinkage and expansion of the samples during heating and cooling, respectively. The dilatometry samples were heated from room temperature to $900^{\circ} \mathrm{C}$ and cooled at the same rate of $7.5^{\circ} \mathrm{C} / \mathrm{min}$. The average grain size was measured by the linear intercept method with the use of a correction factor of 1.56 after Mendelson. ${ }^{18}$ The lattice parameters were determined by least-squares refinement of XRD data, obtained using $\mathrm{Cu} K \alpha$ with $\mathrm{Si}$ as a standard and utilizing the program LCLSO. ${ }^{19}$

\section{Results and Discussion}

The effect of $\mathrm{Ta}_{2} \mathrm{O}_{5}$ alloying on the transformability of Y-TZP was examined by determining the effect on the transformation temperatures, $A_{s}$ and $M_{s}$, of 2 and $3 \mathrm{~mol} \%$ Y-TZP. As shown in Fig. 1, both $A_{s}$ and $M_{s}$ of each Y-TZP increase with the addition of $\mathrm{Ta}_{2} \mathrm{O}_{5}$, so that the chemical driving force for the $t \rightarrow m$ transformation of Y-TZP is enhanced because of the $\mathrm{Ta}_{2} \mathrm{O}_{5}$ alloying. This $\mathrm{Ta}_{2} \mathrm{O}_{5}$ alloying effect is contrasted to the effect of $\mathrm{Y}_{2} \mathrm{O}_{3}$, a stabilizer for TZP, whose addition decreases the transformation temperatures, ${ }^{6}$ Figure 2 compares the alloying effect of $\mathrm{Ta}_{2} \mathrm{O}_{5}$ with that of $\mathrm{HfO}_{2}$ on $M_{s}$ of 2 mol\% Y-TZP. The $\mathrm{HfO}_{2}$ has been known as the only solute which increases the $M_{s}$ temperature. ${ }^{12}$ The increasing trend of $M_{5}$ due to $\mathrm{Ta}_{2} \mathrm{O}_{5}$ alloying is steeper than that due to $\mathrm{HfO}_{2}$ alloying, which implies that $\mathrm{Ta}_{2} \mathrm{O}_{5}$ is a more effective destabilizer for TZP than $\mathrm{HfO}_{2}$. In Fig. 2, the $M_{s}$ temperatures of TZP in the system $\mathrm{ZrO}_{2}-\mathrm{Y}_{2} \mathrm{O}_{3}-\mathrm{Ta}_{2} \mathrm{O}_{5}$ were obtained from specimens sintered for $8 \mathrm{~h}$ at $1500^{\circ} \mathrm{C}$. Those in the system $\mathrm{ZrO}_{2}-\mathrm{Y}_{2} \mathrm{O}_{3}-\mathrm{HfO}_{2}$ were determined after sintering for $18 \mathrm{~h}$ at the same temperature. With these sintering schedules, the influence of grain size on the comparison in Fig. 2 becomes

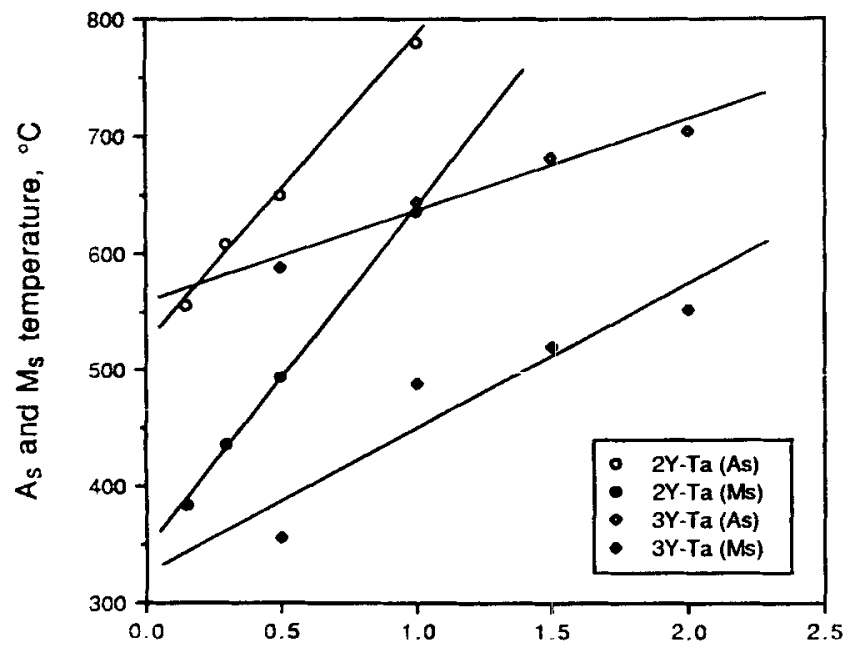

$\mathrm{Ta}_{2} \mathrm{O}_{5}$ content in $\mathrm{Y}-\mathrm{TZP}$, mole \%

Fig. 1. Influence of $\mathrm{Ta}_{2} \mathrm{O}_{5}$ alloying on phase transformation temperatures of 2 and $3 \mathrm{~mol} \%$ Y-TZP prepared by sintering at $1500^{\circ} \mathrm{C}$ for $15 \mathrm{~h}$.

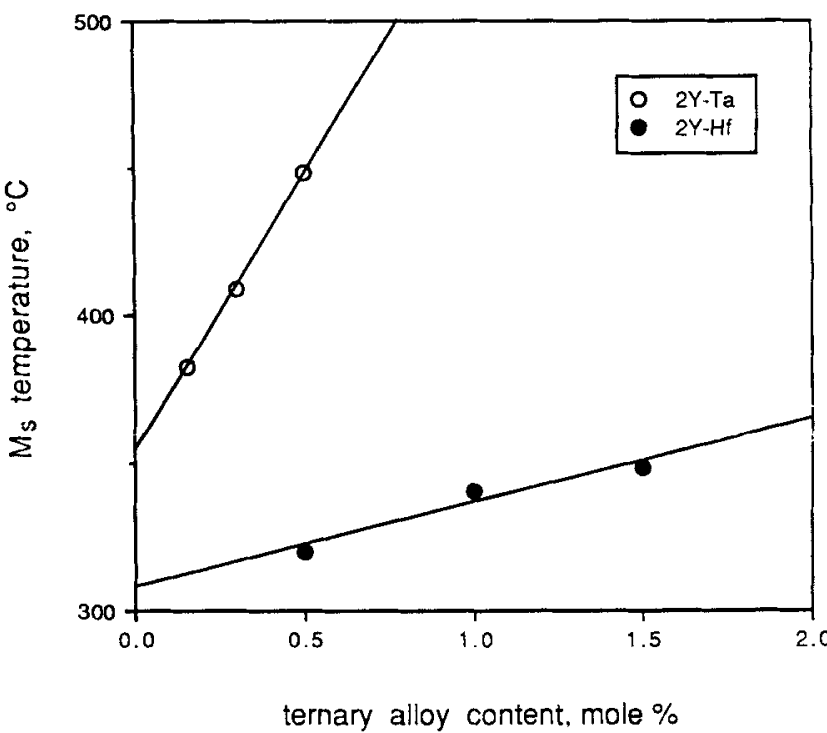

Fig. 2. Comparison of $\mathrm{Ta}_{2} \mathrm{O}_{5}$ and $\mathrm{HfO}_{2}$ alloying effects on $t \rightarrow m$ transformation temperature of $2 \mathrm{~mol} \%$ Y-TZP. Specimens were prepared to have grain sizes of about $1.0 \mu \mathrm{m}$ by sintering at $1500^{\circ} \mathrm{C}$ for different times.

negligible, with both systems having a grain size of about $1.0 \mu \mathrm{m}$. The grain size dependence of the transformability of TZPs in the systems $\mathrm{ZrO}_{2}-\mathrm{Y}_{2} \mathrm{O}_{3}-\mathrm{Ta}_{2} \mathrm{O}_{5}$ and $-\mathrm{HfO}_{2}$ is documented in detail elsewhere. ${ }^{20}$

The alloying effect on the fracture toughness of Y-TZP was investigated and the result is shown in Fig. 3, where $\mathrm{Ta}_{2} \mathrm{O}_{5}$ is added to both 2 and 3 mol\% Y-TZP, $\mathrm{HfO}_{2}$ is added to $2 \mathrm{~mol} \%$ Y-TZP, and $\mathrm{Nb}_{2} \mathrm{O}_{5}$ is added to $3 \mathrm{~mol} \% \mathrm{Y}-\mathrm{TZP}$. The toughness value of the specimen of $2 \mathrm{~mol} \%$ YTZP with $\geq 0.5 \mathrm{~mol} \%$ $\mathrm{Ta}_{2} \mathrm{O}_{5}$ could not be obtained since most of the $t-\mathrm{ZrO}_{2}$ phase transformed to $m-\mathrm{ZrO}_{2}$ phase during sample preparation. The alloying showed little effect on the microstructure of the specimens sintered at $1500^{\circ} \mathrm{C}$ for $1 \mathrm{~h}$. Typically, the grain size of TZPs in the system $\mathrm{ZrO}_{2}-\mathrm{Y}_{2} \mathrm{O}_{3}-\mathrm{Ta}_{2} \mathrm{O}_{5}$ was determined to be about $0.5 \mu \mathrm{m}$ for all alloy additions. ${ }^{20}$ The density of the specimens was $\geq 97 \%$ of the theoretical density. No $m-\mathrm{ZrO}_{2}$ phase was detected in the as-sintered specimens, except in the sample with $1.5 \mathrm{~mol} \% \mathrm{Ta}_{2} \mathrm{O}_{5}$ which contained about $8 \%$ $m-\mathrm{ZrO}_{2}$. The fracture toughness increases from 5 to about

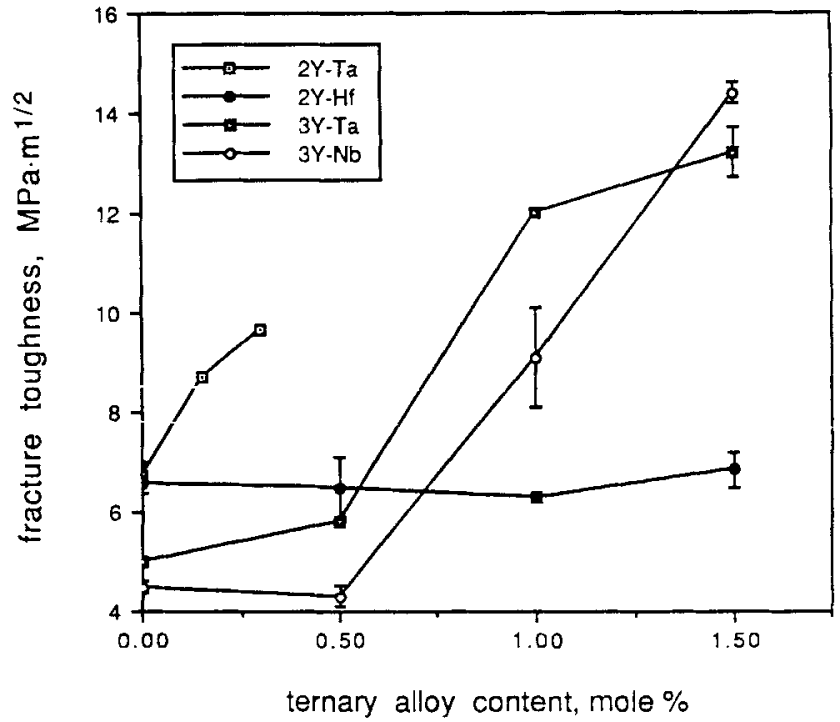

Fig. 3. $\mathrm{Ta}_{2} \mathrm{O}_{5}, \mathrm{Nb}_{2} \mathrm{O}_{5}$, and $\mathrm{HfO}_{2}$ alloying effects on fracture toughness of 2 and 3 mol\% Y-TZP prepared by sintering at $1500^{\circ} \mathrm{C}$ for $1 \mathrm{~h}$. 
$14 \mathrm{MPa} \cdot \mathrm{m}^{1 / 2}$ as the $\mathrm{Ta}_{2} \mathrm{O}_{5}$ or $\mathrm{Nb}_{2} \mathrm{O}_{5}$ concentration in $3 \mathrm{~mol} \%$ YTZP increases from zero to $1.5 \mathrm{~mol} \%$. This remarkable increase in the toughness is attributed to the enhanced transformability of $t-\mathrm{ZrO}_{2}$ due to the alloying shown in Fig. 1. The influence of $\mathrm{Nb}_{2} \mathrm{O}_{5}$ alloying is similar to that due to $\mathrm{Ta}_{2} \mathrm{O}_{5}$ but the effect of $\mathrm{HfO}_{2}$ alloying is not noticeable as compared with that of $\mathrm{Ta}_{2} \mathrm{O}_{5}$ alloying. The trends of $\mathrm{Ta}_{2} \mathrm{O}_{5}$ and $\mathrm{HfO}_{2}$ alloying effects on the fracture toughness of $2 \mathrm{~mol} \%$ Y-TZP are analogous to those on the $M_{s}$ temperature shown in Fig. 2. Thus, $\mathrm{Ta}_{2} \mathrm{O}_{5}$ and $\mathrm{Nb}_{2} \mathrm{O}_{5}$ are strong destabilizers which enhance the transformability of Y-TZP, as compared with $\mathrm{HfO}_{2}$. Figure 4 shows the $\mathrm{Ta}_{2} \mathrm{O}_{5}$ alloying effect on the bending strength and $m-\mathrm{ZrO}_{2}$ fraction on the polished surface of $3 \mathrm{~mol} \%$ YTZP. The bending strength slightly increases with the addition of $\mathrm{Ta}_{2} \mathrm{O}_{5}$ up to $1.0 \mathrm{~mol} \%$ and decreases with further addition of $\mathrm{Ta}_{2} \mathrm{O}_{5}$. This decrease in the bending strength of the samples with $1.5 \mathrm{~mol}^{\%} \mathrm{Ta}_{2} \mathrm{O}_{5}$ is due to the presence of a large amount of $m-\mathrm{ZrO}_{2}$ phase on the polished sample surface. Increasing the sintering time, which results in grain growth, causes a further drop in the strength of the samples with $1.5 \mathrm{~mol} \% \mathrm{Ta}_{2} \mathrm{O}_{5}$ due to the increased amount of $m-\mathrm{ZrO}_{2}$ phase. ${ }^{20}$ The alloying effect on the transformability has been demonstrated by measuring the $m-\mathrm{ZrO}_{2}$ phase fraction on the fracture surface of the bend test specimens, where the increasing trend of $m-\mathrm{ZrO}_{2}$ fraction after the fracture as a function of $\mathrm{Ta}_{2} \mathrm{O}_{5}$ content shows excellent correlation with the fracture toughness. ${ }^{20}$ The fracture toughness values measured by the multiple-crack method were identical to those obtained by indentation as long as the minimum requirement of $c \geq 2 a$ suggested by Anstis $e t a l{ }^{16}$ is met, where $c$ and $a$ are the half crack length from a Vickers diamond pyramid indent and the half diagonal of the indent, respectively. Otherwise, the values by the indentation technique are overestimated by about $10 \%$ to $15 \%$ as compared with the values by the multiplecrack method. ${ }^{20}$ This is the case for the specimens with 1.0 and $1.5 \mathrm{~mol} \% \mathrm{Ta}_{2} \mathrm{O}_{5}$ or $\mathrm{Nb}_{2} \mathrm{O}_{5}$ after indentation with the maximum load of $490 \mathrm{~N}$ employed in the present study.

The effects of $\mathrm{Ta}_{2} \mathrm{O}_{5}, \mathrm{Nb}_{2} \mathrm{O}_{5}$, and $\mathrm{HfO}_{2}$ alloying on the changes in the $c / a$ axial ratio (tetragonality) of YTZP are illustrated in Fig. 5, and the lattice parameters of the resulting $t-\mathrm{ZrO}_{2}$ solid solutions at room temperature are listed in Table I. As shown, the alloying of these oxides into Y-TZP increases the tetragonality. On the other hand, the addition of oxides such as $\mathrm{Y}_{2} \mathrm{O}_{3}, \mathrm{Yb}_{2} \mathrm{O}_{3}, \mathrm{Gd}_{2} \mathrm{O}_{3}$, ${ }^{21}$ and $\mathrm{CeO}_{2}{ }^{22,23}$ to stabilize $t-\mathrm{ZrO}_{2}$ is found to decrease the tetragonal distortion as summarized in Fig. 6. This is the exactly opposite effect of the alloying of $\mathrm{Ta}_{2} \mathrm{O}_{5}, \mathrm{Nb}_{2} \mathrm{O}_{5}$, and $\mathrm{HfO}_{2}$ which enhances the

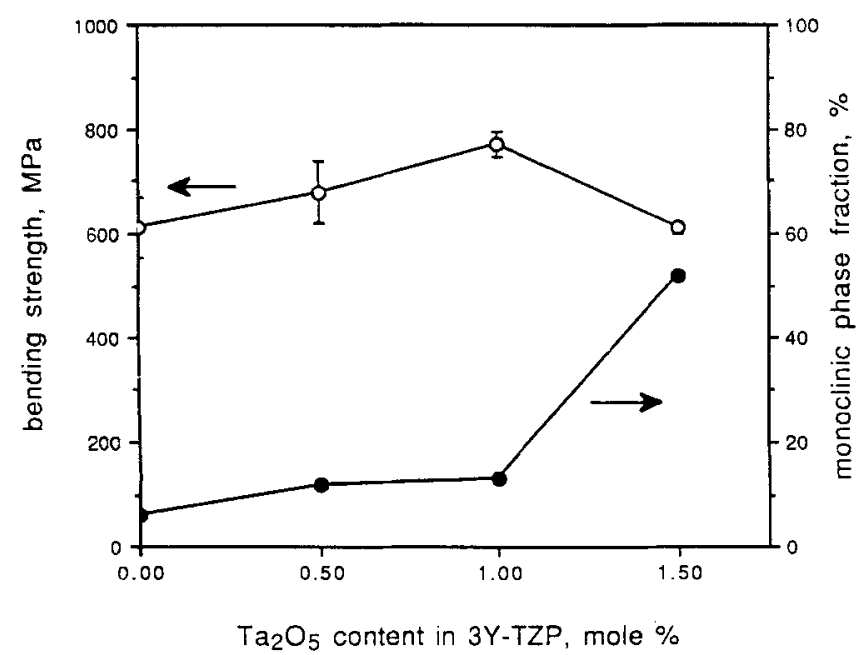

Fig. 4. Influence of $\mathrm{Ta}_{2} \mathrm{O}_{5}$ alloying on four-point bending strength and $m-\mathrm{ZrO}_{2}$ phase content on polished surface of $3 \mathrm{~mol} \%$ Y-TZP prepared by sintering at $1500^{\circ} \mathrm{C}$ for $1 \mathrm{~h}$.

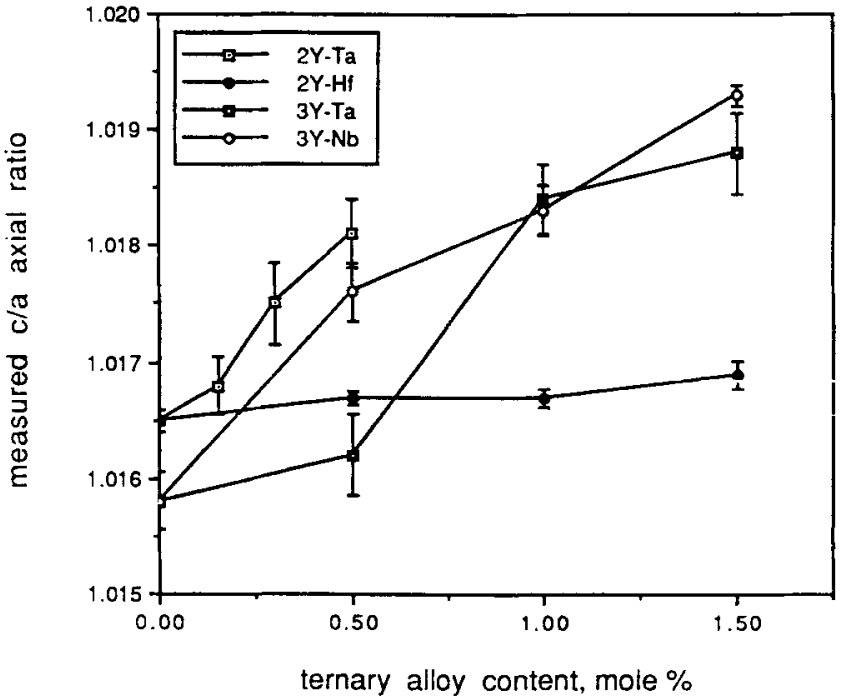

Fig. 5. $\mathrm{Ta}_{2} \mathrm{O}_{5}, \mathrm{Nb}_{2} \mathrm{O}_{5}$, and $\mathrm{HfO}_{2}$ alloying effects on $c / a$ axial ratio of 2 and 3 mol\% YTRP.

transformability of YTZP. Thus the destabilizer and the stabilizer for the $t-\mathrm{ZrO}_{2}$ might be differentiated depending on its role in the changes of the tetragonality of the resulting solid solution. Again, the effects of $\mathrm{Ta}_{2} \mathrm{O}_{5}$ and $\mathrm{Nb}_{2} \mathrm{O}_{5}$ alloying on the tetragonality are distinguished from the effect of $\mathrm{HfO}_{2}$. In particular, the influences of $\mathrm{Ta}_{2} \mathrm{O}_{5}$ and $\mathrm{HfO}_{2}$ alloying on the tetragonality of 2 mol\% Y-TZP as shown in Fig. 5 are consistent with those on the $M_{s}$ temperature and fracture toughness, as illustrated in Figs. 2 and 3, respectively. To see how the transformability of these ternary TZPs changes with the tetragonality, the $M_{s}$ temperatures of the system $\mathrm{ZrO}_{2}-$ $\mathrm{Y}_{2} \mathrm{O}_{3}-\mathrm{Ta}_{2} \mathrm{O}_{5}$ shown in Fig. 1 are plotted as a function of the tetragonality in Fig. 7, where it can be seen that the $M_{s}$ temperature of 2 and $3 \mathrm{~mol} \%$ Y-TZP increases linearly with increasing tetragonality. The effect of the tetragonality on the transformability is apparent in Fig. 8, where the fracture toughness values are from Fig. 3. As a result, at least phenomenologically, the alloying effect on the transformability of TZP is closely related to the effect on the tetragonality of $t-\mathrm{ZrO}_{2}$ solid solution in such a way that the transformability increases with the tetragonality.

The relationship between transformability and tetragonality is supported by consideration of $t^{\prime}-\mathrm{ZrO}_{2}$, which is known as nontransformable $t-\mathrm{ZrO}_{2}{ }^{10,24}$ The $c / a$ ratio of $t^{\prime}-\mathrm{ZrO}_{2}$ in the system $\mathrm{Y}_{2} \mathrm{O}_{3}-\mathrm{ZrO}_{2}$ is closer to unity than that of transformable $t-\mathrm{ZrO}_{2}$ with the same concentration of $\mathrm{Y}_{2} \mathrm{O}_{3}$ in the range from 10.9 to $13.0 \mathrm{~mol}_{\%} \mathrm{YO}_{1.5},{ }^{25}$ where the tetragonality of the transformable $t-\mathrm{ZrO}_{2}$ is already small. The even smaller tetragonality of $t^{\prime}-\mathrm{ZrO}_{2}$ is likely responsible for its nontransformability. Another indication is in the system $\mathrm{Y}_{2} \mathrm{O}_{3}-\mathrm{CeO}_{2}-\mathrm{ZrO}_{2}$, where the substitution of $\mathrm{Y}_{2} \mathrm{O}_{3}$ for $\mathrm{CeO}_{2}$ causes a decrease in the fracture toughness and an increase of the phase stability of $\mathrm{Ce}-\mathrm{TZP}{ }^{26}$ This $\mathrm{Y}_{2} \mathrm{O}_{3}$ alloying effect is predictable since the decrease in the tetragonality due to $\mathrm{Y}_{2} \mathrm{O}_{3}$ is more pronounced than that due to $\mathrm{CeO}_{2}$, as shown in Fig. 6. The alloying effect of $\mathrm{Y}_{2} \mathrm{O}_{3}$ and $\mathrm{CeO}_{2}$ on tetragonality is consistent with that on the $m \rightarrow t$ transformation temperature; that is, the decrease in $A_{s}$ temperature per mole percent solute is reported to be $170.7^{\circ} \mathrm{C}$ for $\mathrm{YO}_{1.5}$ and $71.2^{\circ} \mathrm{C}$ for $\mathrm{CeO}_{2}{ }^{27}$ Evidently, $t-\mathrm{ZrO}_{2}$ solid solutions become unstable as their tetragonality increases toward 1.020 (Fig. 6), which corresponds to the $b / a$ axial ratio of $m-\mathrm{ZrO}_{2}$ at room temperature. ${ }^{28}$ On the other hand, they become stable as the tetragonality decreases toward unity, which corresponds to $c-\mathrm{ZrO}_{2}$. This relationship allows the classification of oxides into either a stabilizer (decreasing tetragonality) or a destabilizer (increasing tetragonality) for the $t-\mathrm{ZrO}_{2}$ phase at room temperature. 
Table I. Comparison of Measured and Calculated Lattice Parameters of $t-\mathrm{ZrO}_{2}$ Solid Solutions

\begin{tabular}{|c|c|c|c|c|c|c|c|c|}
\hline \multirow{2}{*}{\multicolumn{3}{|c|}{ Composition (mol\%) }} & \multicolumn{2}{|c|}{$a(n m)$} & \multirow[b]{2}{*}{$\Delta a(\%)^{*}$} & \multicolumn{2}{|c|}{$c(\mathrm{~nm})$} & \multirow[b]{2}{*}{$\Delta c(\%)^{*}$} \\
\hline & & & Measd & Calcd & & Measd & Calcd & \\
\hline $\begin{array}{l}\mathrm{ZrO}_{2} \\
98.0\end{array}$ & $\begin{array}{c}\mathrm{Y}_{2} \mathrm{O}_{3} \\
2\end{array}$ & $\begin{array}{c}\mathrm{Ta}_{2} \mathrm{O}_{5} \\
0.0\end{array}$ & 0.50971 & 0.50982 & -0.02 & 0.51812 & 0.51785 & 0.05 \\
\hline 97.85 & 2 & 0.15 & 0.50966 & 0.50979 & -0.03 & 0.51820 & 0.51798 & 0.04 \\
\hline 97.7 & 2 & 0.3 & 0.50961 & 0.50975 & -0.03 & 0.51851 & 0.51811 & 0.08 \\
\hline 97.5 & 2 & 0.5 & 0.50930 & 0.50971 & -0.08 & 0.51854 & 0.51828 & 0.05 \\
\hline 97.0 & 3 & 0.0 & 0.50984 & 0.51041 & -0.11 & 0.51792 & 0.51735 & 0.11 \\
\hline 96.5 & 3 & 0.5 & 0.51024 & 0.51030 & -0.01 & 0.51849 & 0.51778 & 0.14 \\
\hline 96.0 & 3 & 1.0 & 0.50984 & 0.51019 & -0.07 & 0.51924 & 0.51819 & 0.20 \\
\hline 95.5 & 3 & 1.5 & 0.50989 & 0.51007 & -0.04 & 0.51949 & 0.51861 & 0.17 \\
\hline $\mathrm{ZrO}_{2}$ & $\mathrm{Y}_{2} \mathrm{O}_{3}$ & $\mathrm{Nb}_{2} \mathrm{O}_{5}$ & & & & & & \\
\hline 96.5 & 3 & 0.5 & 0.50962 & 0.51030 & -0.13 & 0.51857 & 0.51778 & 0.15 \\
\hline 96.0 & 3 & 1.0 & 0.50968 & 0.51019 & -0.10 & 0.51903 & 0.51819 & 0.16 \\
\hline 95.5 & 3 & 1.5 & 0.50967 & 0.51007 & -0.08 & 0.51950 & 0.51861 & 0.17 \\
\hline $\mathrm{ZrO}_{2}$ & $\mathrm{Y}_{2} \mathrm{O}_{3}$ & $\mathrm{HfO}_{2}$ & & & & & & \\
\hline $97.5^{\circ}$ & 2 & 0.5 & 0.50957 & 0.50981 & -0.05 & 0.51810 & 0.51784 & 0.05 \\
\hline 97.0 & 2 & 1.0 & 0.50960 & 0.50980 & -0.04 & 0.51809 & 0.51783 & 0.05 \\
\hline 96.5 & 2 & 1.5 & 0.50951 & 0.50978 & -0.05 & 0.51813 & 0.51782 & 0.06 \\
\hline
\end{tabular}

*[(measured value - calculated value $) /($ measured value $)] \times 100$.

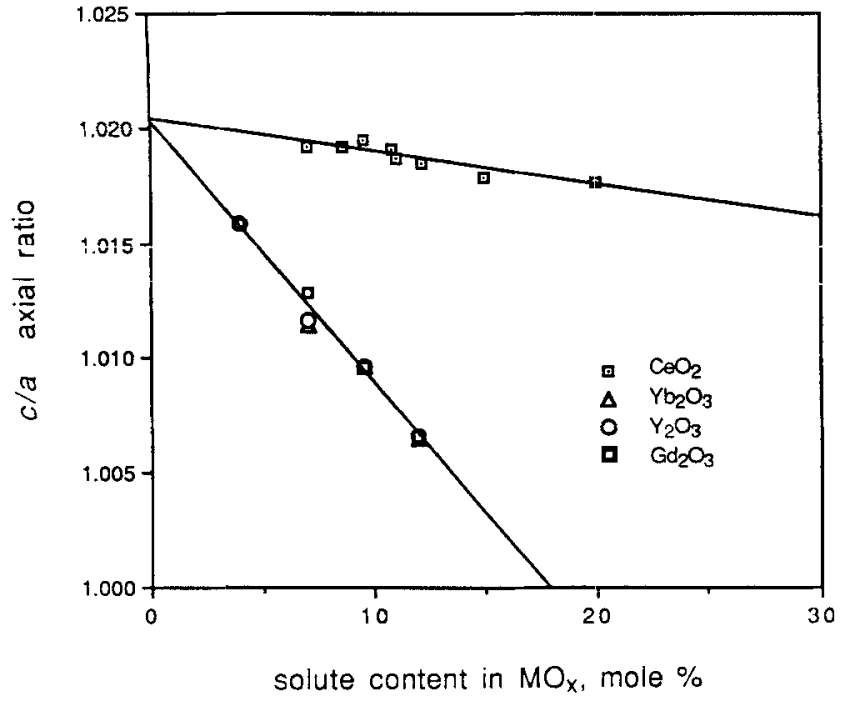

Fig. 6. Compositional dependence of $c / a$ axial ratio of $t-\mathrm{ZrO}_{2}$ solid solutions stabilized by various oxides (Refs. 21 to 23 ).

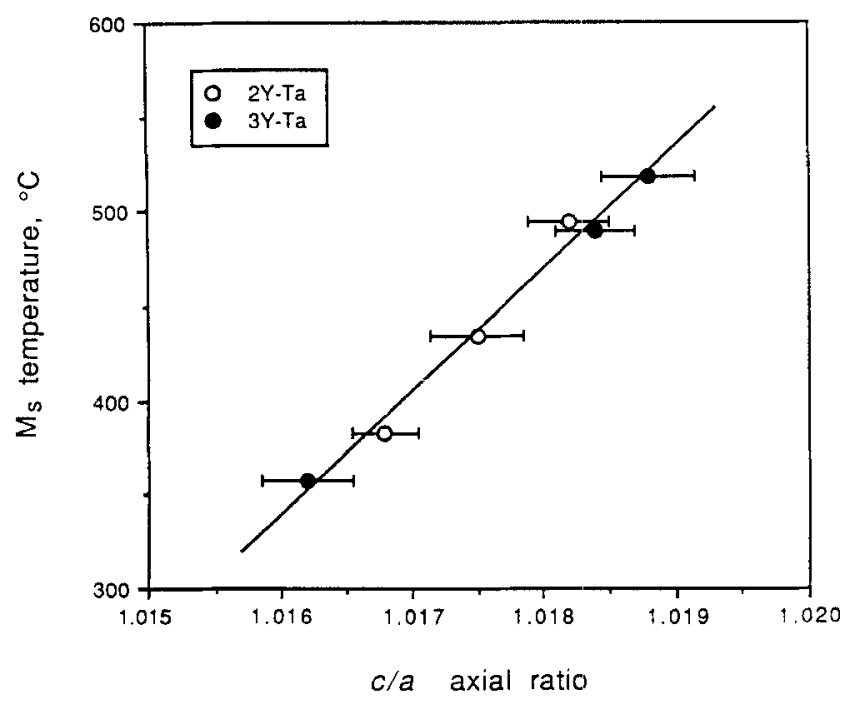

Fig. 7. Relationship between $t \rightarrow m$ transformation temperature and $c / a$ axial ratio of $\mathrm{Y}(\mathrm{Ta})-\mathrm{TZP}$.

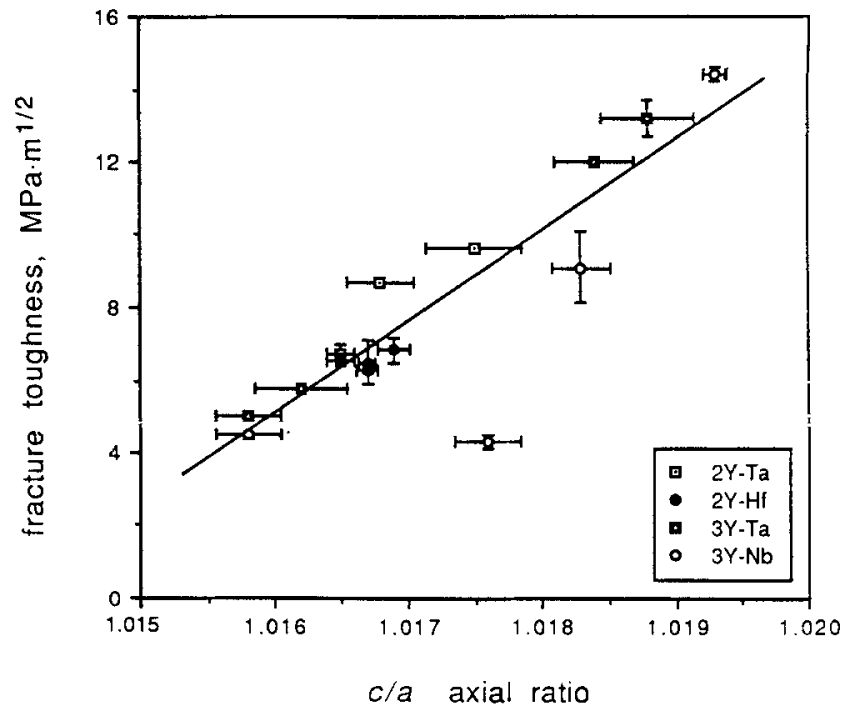

Fig. 8. Fracture toughness as a function of tetragonality.

In order to control the fracture toughness of TZP through alloying, besides the changes in the microstructure, it is desirable to formulate equations which predict changes in the lattice parameters of $t-\mathrm{ZrO}_{2}$ as a result of compositional variations since the tetragonality is related to the transformability. The empirical equations for the changes in the lattice parameters, $a$ and $c$, of $t-\mathrm{ZrO}_{2}$ solid solutions at room temperature are expressed as follows:

$$
\begin{aligned}
& a=0.5086+\sum_{k}\left(0.0255 \Delta r_{k}+0.00015 \Delta z_{k}\right) m_{k} \\
& c=0.5189+\sum_{k}\left(0.0213 \Delta r_{k}+0.00064 \Delta z_{k}\right) m_{k}
\end{aligned}
$$

where $a$ and $c$ are in nanometers, $\Delta r_{k}$ (in nanometers) is the difference in ionic radius $\left(r_{k}-0.084\right)$ of the $k$ th solute cation $\left(r_{k}\right)$ and $\mathrm{Zr}^{4+}(0.084 \mathrm{~nm})$ in eightfold coordination from Shannon's compilation, ${ }^{29} \Delta z_{k}$ is the cation valency difference $\left(z_{k}-4\right)$, and $m_{k}$ is the mole percent of the $k$ th solute, in the form of $\mathrm{MO}_{x}, x=z_{k} / 2$. The term $m_{k}$, which corresponds to $M_{k}$ for $n_{k}=1$, is calculated by

$$
m_{k}=\frac{n_{k} M_{k}}{100+\sum_{k}\left(n_{k}-1\right) M_{k}} \times 100
$$


where $n_{k}$ is the number of cations in the $k$ th solute oxide, and $M_{k}$ is the concentration of the $k$ th solute oxide in mole percent (e.g., $n_{k}$ is 2 and $M_{k}$ is 3 for $3 \mathrm{~mol} \% \mathrm{Y}_{2} \mathrm{O}_{3}$ ). The constants in Eqs. (1) and (2) were determined from regression analyses of $t-\mathrm{ZrO}_{2}$ lattice parameters in the systems $\mathrm{Y}_{2} \mathrm{O}_{3}-,, 10,21,30$ $\mathrm{Yb}_{2} \mathrm{O}_{3}-,{ }^{21,30} \mathrm{Gd}_{2} \mathrm{O}_{3}-,{ }^{21,30}$ and $\mathrm{CeO}_{2}-\mathrm{ZrO}_{2}{ }^{22,23}$ The details of the formalism of Eqs. (1) and (2) are described elsewhere. ${ }^{31}$ To illustrate, the changes in the lattice parameters of $t-\mathrm{ZrO}_{2}$ in the system $\mathrm{Y}_{2} \mathrm{O}_{3}-\mathrm{ZrO}_{2}$ as a function of the mole percent $\mathrm{YO}_{1.5}$ can be represented as

$$
\begin{aligned}
& a=0.5086+0.00031 m_{\mathrm{Y}} \\
& c=0.5189-0.00026 m_{\mathrm{Y}}
\end{aligned}
$$

by using $\Delta r_{Y}=0.0179\left(r_{Y^{3+}}=0.1019 \mathrm{~nm}\right)$ and $\Delta z_{Y}=-1$. Equations (4) and (5) are in excellent agreement with the equations determined experimentally by Toraya. ${ }^{32}$ This suggests that the equations for the lattice parameters of $t-\mathrm{ZrO}_{2}$ in the system $\mathrm{Y}_{2} \mathrm{O}_{3}-\mathrm{CeO}_{2}-\mathrm{ZrO}_{2}$, proposed by Urabe et al., ${ }^{27}$ should be

$$
\begin{aligned}
& a=0.5086+0.00031 m_{\mathrm{Y}}+0.00033 m_{\mathrm{Ce}} \\
& c=0.5189-0.00026 m_{\mathrm{Y}}+0.00028 m_{\mathrm{Ce}}
\end{aligned}
$$

from $\Delta r_{\mathrm{Ce}}=0.013\left(r_{\mathrm{Ce}^{4+}}=0.097 \mathrm{~nm}\right)$ and $\Delta z_{\mathrm{Ce}}=0$. The only significant discrepancy between Eqs. (6) and (7) and those determined by Urabe et al. is the coefficient of $m_{Y}$ in Eq. (6), which was 0.00052 .

The calculated lattice parameters using Eqs. (1) and (2) are compared with the measured values in Table I. Considering the standard error $(0.00030 \mathrm{~nm})$ from the regression analyses in Eqs. (1) and (2) and the experimental error in the measurements, which ranges from 0.00001 to $0.00015 \mathrm{~nm}$, the agreement between the calculated and measured lattice parameters is remarkable. Another good agreement can be found in the system $\mathrm{MgO}-\mathrm{Y}_{2} \mathrm{O}_{3}-\mathrm{ZrO}_{2},{ }^{33}$ where the measured values for $a$ and $c$ of $t-\mathrm{ZrO}_{2}$ were reported to be 0.5114 and $0.5136 \mathrm{~nm}$, respectively, for $M_{\mathrm{Mg}}=2.6$ and $M_{Y}=4.5$ (i.e., $m_{\mathrm{Mg}}=2.5$ and $m_{\mathrm{Y}}=8.6$ ). These values are very close to the calculated $a$ and $c$ from Eqs. (1) and (2), which are 0.5108 and $0.5138 \mathrm{~nm}$, respectively (here, $r_{\mathrm{Mg}}=0.089 \mathrm{~nm}$ and $\left.\Delta z_{\mathrm{Mg}}=-2\right)$. Accordingly, these equations can be applied to predict the effect of alloying on the tetragonality of $t-\mathrm{ZrO}_{2}$ solid solutions as shown in Fig. 9. Comparison of Figs. 9 and 5 shows good qualitative agreement. In Fig. 9 the alloying effects of $\mathrm{Ta}_{2} \mathrm{O}_{5}$ and $\mathrm{Nb}_{2} \mathrm{O}_{5}$ on the tetragonality are estimated to be the same since the ionic radii in eightfold coordination

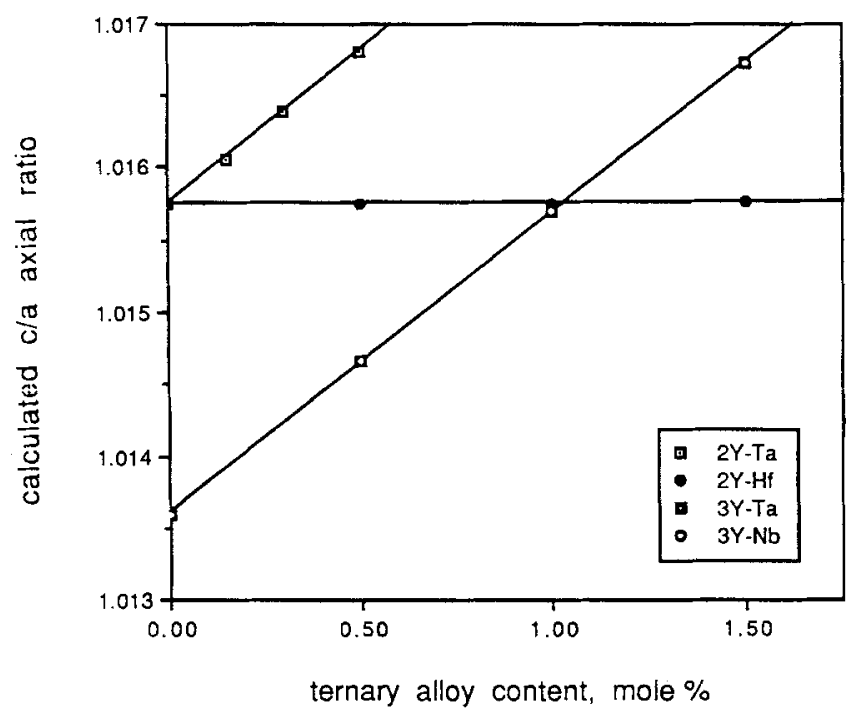

Fig. 9. Calculated $c / a$ axial ratio by using Eqs. (1) and (2) as a function of ternary element content in Y-TZP.
$(0.074 \mathrm{~nm})$ and valencies of $\mathrm{Ta}^{5+}$ and $\mathrm{Nb}^{5+}$ are identical. The small influence of $\mathrm{HfO}_{2}$ alloying is clearly due to the same valency and the similar ionic radii of $\mathrm{Zr}^{4+}(0.084 \mathrm{~nm})$ and $\mathrm{Hf}^{4+}(0.083 \mathrm{~nm})$. It should be noted that the equations for the lattice parameters contain factors such as ionic radius, valency, and concentration of solute cation which are considered to influence the stabilization of the $t-\mathrm{ZrO}_{2}$ phase, as discussed in the earlier section. Consequently, Eqs. (1) and (2) might be used to design TZP with a desired transformability by classifying solute oxides according to their influence on the tetragonality.

\section{Conclusion}

The addition of $\mathrm{Ta}_{2} \mathrm{O}_{5}, \mathrm{Nb}_{2} \mathrm{O}_{5}$, and $\mathrm{HfO}_{2}$ to $\mathrm{Y}_{2} \mathrm{O}_{3}-$ stabilized tetragonal $\mathrm{ZrO}_{2}$ (Y-TZP) gives rise to the high transformability of the resulting TZP. The enhanced transformability of Y-TZP is related to the alloying effect on the tetragonality of Y-TZP, so that the addition of these oxides increases the tetragonal distortion of the cubic fluorite lattice. The trend of increasing the tetragonality due to alloying is consistent with those of enhancing fracture toughness and $t \rightarrow m$ transformation temperature. The changes in the tetragonality due to the alloying are in remarkable agreement with the prediction by the proposed empirical equations.

Acknowledgments: The author thanks P. F, Becher and S. D. Nunn for valuable discussions.

\section{References}

${ }^{1}$ D. K. Hohnke, "Ionic Conductivity of $\mathrm{Zr}_{1-x} \mathrm{In}_{2 x} \mathrm{O}_{2-x}$," J. Phys. Chem. Solids, 41 [7] 777-84 (1980).

${ }^{2}$ E. C. Subbarao, "Zirconia-An Overview"; pp. 1-24 in Advances in Ceramics, Vol. 3, Science and Technology of Zirconia. Edited by A. H. Heuer and L.W. Hobbs, American Ceramic Saciety, Columbus, OH, 1981

${ }^{3}$ T. K. Gupta, J. H. Bechtold, R. C. Kuznicki, L. H. Cadoff, and B. R. Rossing, "Stabilization of Tetragonal Phase in Polycrystalline Zirconia," J. Mater. Sci., 12 [12] 2421-26 (1977).

${ }^{4}$ T. K. Gupta, F. F. Lange, and J. H. Bechtold, "Effect of Stress-Induced Phase Transformation on the Properties of Polycrystalline Zirconia Containing Metastable Tetragonal Phase," J. Mater. Sci., 13 [7] 1464-70 (1978).

${ }^{5}$ F. F. Lange, "Transformation Toughening: Part 3, Experimental Observations in the $\mathrm{ZrO}_{2}-\mathrm{Y}_{2} \mathrm{O}_{3}$ System," J. Mater. Sci., 17 [1] 240-46 (1982).

${ }^{6}$ R. Ruh, K. S. Mazdiyasni, P. G. Valentine, and H.O. Bielstein, "Phase Relations in the System $\mathrm{ZrO}_{2}-\mathrm{Y}_{2} \mathrm{O}_{3}$ at Low $\mathrm{Y}_{2} \mathrm{O}_{3}$ Contents," J. Am. Ceram. Soc., 67 [9] C-190-C-192 (1984).

${ }^{7}$ S. Schmauder and H. Schubert, "Significance of Internal Stresses for the Martensitic Transformation in Yttria-Stabilized Tetragonal Zirconia Polycrystals During Degradation," J. Am. Ceram. Soc., 69 [7] 534-40 (1986).

${ }^{8} \mathrm{~K}$. Tsukuma, Y. Kubota, and T. Tsukidate, "Thermal and Mechanical Properties of $\mathrm{Y}_{2} \mathrm{O}_{3}$-Stabilized Tetragonal Zirconia Polycrystals"; pp. 382-90 in Advances in Ceramics, Vol. 12, Science and Technology of Zirconia II. Edited by N. Claussen, M. Rühle, and A. H. Heuer. American Ceramic Society, Columbus, $\mathrm{OH}, 1984$

${ }^{9} \mathrm{H}$. Schubert, "Anisotropic Thermal Expansion Coefficients of $\mathrm{Y}_{2} \mathrm{O}_{3}$ Stabilized Tetragonal Zirconia," J. Am. Ceram. Soc., 69 [3] 270-71 (1986).

${ }^{10}$ H. G. Scott, "Phase Relationships in the Zirconia-Yttria System," J. Mater. Sci., 10 [9] 1527-35 (1975).

${ }^{11}$ R. Ruh, H. Garrett, R. F. Domagala, and N.M. Tallan, "The System Zirconia-Hafnia," J. Am. Ceram. Soc., 51 [1] 23-27 (1968).

${ }^{12} \mathrm{~N}$. Claussen, F. Sigulinski, and M. Rühle, "Phase Transformation of Solid Solutions of $\mathrm{ZrO}_{2}$ and $\mathrm{HfO}_{2}$ in an $\mathrm{Al}_{2} \mathrm{O}_{3}$ Matrix"; pp. 164-67 in Advances in Ceramics, Vol. 3, Science and Technology of Zirconia. Edited by A. H. Heuer and L.W. Hobbs. American Ceramic Society, Columbus, OH, 1981.

${ }^{13} \mathrm{~N}$. Claussen, "Microstructural Design of Zirconia-Toughened Ceramics (ZTC)"' pp. 325-51 in Advances in Ceramics, Vol. 12, Science and Technology of Zirconia II. Edited by N. Claussen, M. Rühle, and A. H. Heuer. American Ceramic Society, Columbus, OH, 1984.

${ }^{14} \mathrm{~S}$. Burke and R. Garvie, "Soft Phonon Modes and the MonoclinicTetragonal Phase Transformations in Zirconia and Hafnia," $\boldsymbol{J}$. Mater. Sci. Lett., 12 [7] 1487-90 (1977).

${ }^{15}$ R. F. Cook and B. R. Lawn, "A Modified Indentation Toughness Technique," J. Am. Ceram. Soc., 66 [11] C-200-C-201 (1983).

${ }^{16}$ G. R. Anstis, P. Chantikul, B. R. Lawn, and D. B. Marshall, "A Critical Evaluation of Indentation Techniques for Measuring Fracture Toughness: I, Direct Crack Measurements," J. Am. Ceram. Soc., 64 [9] 533-38 (1981).

${ }^{17}$ R. C. Garvie and P. S. Nicholson, "Phase Analysis in Zirconia Systems," J. Am. Ceram. Soc., 55 [6] 303-305 (1972).

${ }^{18}$ M. I. Mendelson, "Average Grain Size in Polycrystalline Ceramics," J. Am. Ceram. Soc., 52 [8] 443-46 (1969). 
${ }^{19} \mathrm{C}$. W. Burnham, "Lattice Constant Refinement," Carnegie Institution of Washington Year Book 61, 132-35 (1962)

${ }^{20}$ D.-J. Kim, "The Effect of Alloying on the Transformability of $\mathrm{Y}_{2} \mathrm{O}_{3}$. Stabilized Tetragonal $\mathrm{ZrO}_{2}$ "; $\mathrm{Ph} . \mathrm{D}$. Dissertation. University of Michigan, Ann Arbor, MI, August 1988.

${ }^{21}$ J. Lefevre, "Different Structural Modifications of Fluorite Type Phases in Zirconium or Hafnium Oxide Based Systems," Ann. Chim. (Paris), 8 [1-2] 117-49 (1963).

${ }^{22} \mathrm{~K}$. Tsukuma and M. Shimada, "Strength, Fracture Toughness and Vickers Hardness of $\mathrm{CeO}_{2}$-Stabilized Tetragonal $\mathrm{ZrO}_{2}$ Polycrystals (Ce-TZP), J. Mater. Sci., 20 [4] 1178-84 (1985).

${ }^{23} \mathrm{E}$. Tani, M. Yoshimura, and S. Somiya, "Revised Phase Diagram of the System $\mathrm{ZrO}_{2}-\mathrm{CeO}_{2}$ Below $1400^{\circ} \mathrm{C}$," J. Am. Ceram. Soc., 66 [7] 506-10 (1983)

${ }^{24}$ R. A. Miller, J. L. Smialek, and R. G. Garlick, "Phase Stability in Plasma-Sprayed, Partially Stabilized Zirconia-Yttria"; pp. 241-53 in Advances in Ceramics, Vol. 3, Science and Technology of Zirconia. Edited by A. H. Heuer and L.W. Hobbs. American Ceramic Society, Columbus, $\mathrm{OH}, 1981$.

${ }^{25}$ A. Paterson and R. Stevens, "Phase Analysis of Sintered Yttria-Zirconia Ceramics by X-ray Diffraction," J. Mater. Res., 1 [2] 295-99 (1986).
${ }^{26}$ J.-G. Duh, H.-T. Dai, and B.-S. Chiou, "Sintering, Microstructure, Hardness, and Fracture Toughness Behavior of $\mathrm{Y}_{2} \mathrm{O}_{3}-\mathrm{CeO}_{2}-\mathrm{ZrO}_{2}$, " J. Am Ceram. Soc., 71 [10] 813-19 (1988).

${ }^{27}$ K. Urabe, K. Ogata, H. Ikawa, S. Udagawa, and O. Meguroku, "Phase Transformation and Lattice Constants of Zirconia Solid Solutions in the System $\mathrm{Y}_{2} \mathrm{O}_{3}-\mathrm{CeO}_{2}-\mathrm{ZrO}_{2}$," Mater. Sci. Forum, 34-36, 147-52 (1988).

${ }^{28}$ Powder Diffraction File, Card No. 24-1165 A. Joint Committee on Powder Diffraction Standards, Swarthmore, PA, 1974

${ }^{29}$ R. D. Shannon, "Revised Effective Ionic Radii and Systematic Studies of Interatomic Distances in Halides and Chalcogenides," Acta Crystallogr., Sect. A, 32 [5] 751-67 (1976).

${ }^{30}$ D. Michel, L. Mazerolles, and M. P.Y. Jorba, "Fracture of Metastable Tetragonal Zirconia Crystals," J. Mater. Sci., 18 [9] 2618-28 (1983).

${ }^{31}$ D.-J. Kim, "Lattice Parameters, Ionic Conductivities, and Solubility Limits in Fluorite-Structure $\mathrm{MO}_{2}$ Oxide $\left(\mathrm{M}=\mathrm{Hf}^{4+}, \mathrm{Zr}^{4+}, \mathrm{Ce}^{4+}, \mathrm{Th}^{4+}, \mathrm{U}^{4+}\right)$ Solid Solutions," J. Am. Ceram. Soc., 72 [8] 1415-21 (1989).

${ }^{32} \mathrm{H}$. Toraya, "Effect of $\mathrm{YO}_{1.5}$ Dopant on Unit-Cell Parameters of $\mathrm{ZrO}_{2}$ at Low Contents of $\mathrm{YO}_{1.5}$, J. Am. Ceram. Soc., 72 [4] 662-64 (1989).

${ }^{33}$ R.-R. Lee and A.H. Heuer, "Morphology of Tetragonal $\mathrm{ZrO}_{2}$ in a Ternary (Mg,Y)-PSZ," J. Am. Ceram. Soc., 70 [4] 208-13 (1987). 